\title{
Pattern of various congenital anomalies: A hospital based study
}

\author{
Vishal M. Sharma ${ }^{1, *}$, Bhavesh B. Airao ${ }^{2}$, Ravi A. Zala ${ }^{3}$, Manish R. Pandya ${ }^{4}$ \\ ${ }^{1}$ Resident Doctor, ${ }^{2}$ Associate Professor, ${ }^{3}$ Resident Doctor, ${ }^{4}$ Professor and HOD, Dept. of Obstetrics and Gynecology, C. U Shah \\ Medical College and Hospital, Gujarat, ${ }^{4}$ Scientific Research Institute, Surendranagar, Gujarat, India
}

*Corresponding Author: Vishal M. Sharma

Email: sharmavsh1969@gmail.com

Received: $8^{\text {th }}$ January, 2018

Accepted: $31^{\text {st }}$ October, 2018

\begin{abstract}
Aim of the Study: To know the frequency of different structural congenital anomalies in C.U. Shah medical college and hospital, Surendranagar.

Materials and Methods: This study was carried out in Department of Obstetrics and Gynecology, C.U. Shah medical college and hospital, Surendranagar for a period of two year by using ultrasound sonography in second trimester pregnancy, 150 patients who had diagnosed congenital anomalies of fetus were included in this study.

Results: The incidence of congenital anomalies in this study was $2.48 \%$ of the total number of fetus and babies born after 12 weeks of gestation in our hospital during a period of two year. Most common anomaly is CNS anomaly (84\%) followed by CVS anomaly (11.4\%). In craniospinal system most common congenital anomaly is Anencephaly (26\%).

Conclusion: In spite of high institutional deliveries in Surendranagar, India, rate of congenital anomalies remains very high. Increased awareness about preventable risk factors may help in decreasing the rate of congenital anomalies.
\end{abstract}

Keywords: Congenital anomaly, Prevalence.

\section{Introduction}

New born babies come into this world with the good news that the human being with all its diversities and complexities is still going better. Though there are some unfortunate new borns whose birth is surrounded with sadness and worry for the parents because of the congenital anomaly. ${ }^{1}$ Indian people are living in the midst risk factors for congenital anomaly, e.g., universality of marriage, high fertility, large number of unplanned pregnancies, poor coverage of antenatal care, poor maternal nutritional status, high consanguineous marriages rate, and high carrier rate for hemoglobinopathies. As India is the second most populous country with a large number infant born annually with birth defects. We should focus on controlling congenital anomaly. Many population based strategies such as iodization, double fortification of salt, flour fortification with multivitamins, folic acid supplementation, periconceptional care, carrier screening and prenatal screening are some of proven strategies for controlling congenital anomalies. Birth defects known as structural or functional abnormalities in fetus, which are present from birth. The term congenital disorder is considered to have the same meaning and two terms are used interchangeably. ${ }^{1}$ There are many causes for birth defects-some due to hereditary abnormality, some due to chromosomal disorders or genetic disorder and some others due to environmental agents. There are some commonly known birth defects like Anencephaly, hydrocephalus, Down syndrome, cleft lip \& palate, congenital heart disorders to rare birth defects such as cleft foot and hand, aglossia and albinism, to name a few. ${ }^{2}$
Incidence and Prevalence of Birth Defects: The birth prevalence of congenital anomalies in the developing countries are underestimated as deficiency in diagnostic capabilities and lack of reliability. ${ }^{3}$ According to study done by March of Dimes (MOD) Global Report on congenital anomalies, 7.9 million births occur every year worldwide with serious congenital anomalies and 94\% of these births occur in the middle and low income countries. ${ }^{4}$ According to study done by World Health Organization (WHO) and March of Dimes (MOD) congenital anomalies causes $7 \%$ of all neonatal mortality and almost 3.3 million under five deaths. ${ }^{5}$ In India birth defects prevalence varies from 61 to $69.9 / 1000$ live births. Major birth defects include Cardiovascular system defects, neural tube defects (NTDs) and Down syndrome, hemoglobinopathies, G6 PD(glucose-6phosphate dehydrogenase) deficiency, cause $20 \%$ of infant mortality. ${ }^{6}$ There are many factors that significantly increase the risk of congenital anomalies, such as presence of polyhydramnios/oligohydramnios, maternal febrile diseases in the first trimester, past history of abortions, mother with diabetis, hypertensive disorder in pregnancy, previous abortion and history of birth defects in previous fetus. Mother having diabetes mellitus, hypertensive disorder in pregnancy, and hypo/hyperthyroidism shows a positive association. ${ }^{7}$

Birth Defects Registry of India and Fetal Care Research Foundation: Birth Defects Registry of India (BDRI) was instituted in 2001 by Fetal Care Research Foundation 21, a not-for-profit charity trust based in Chennai, for documentation of birth defects in our country. From a modest beginning, BDRI has now enrolled nearly 700 hospitals across 26 states and 3 Union territories and has so far analyzed over 0.7 million 
births of which the most common anomaly has been Neural Tube Defects (NTD). Besides ascertaining a baseline prevalence of birth defects throughout India, BDRI is working to reduce the birth defects and enable families and careers to form Support Groups for various congenital disorders. The Federation of Obstetric and Gynecological Societies of India (FOGSI) has combined with BDRI since 2008 and both work with unison, 2 adopting the same model. ${ }^{8}$

\section{Magnitude of the Problem}

1. Congenital anomalies occurs in approximately 1 in 33 infants and result in approximately 3.2 million birth defect-related disabilities every year. ${ }^{9}$

2. An estimated 270000 newborns die during the first 28 days of life every year from congenital anomalies.

3. Congenital anomalies may result in long-term disability, which may have significant impacts on individuals, families, health-care systems and societies.

4. The most common and serious congenital disorders are CVS defects, neural tube defects (NTDs) and Down syndrome.

5. Congenital anomalies in most of the cases have a environmental, infectious or genetic origin; although in most of the cases it is difficult identify the cause.

6. About 110000 cases of babies born with congenital rubella syndrome can be prevented through timely vaccination of the mothers during childhood and the reproductive years.

7. Many birth anomalies can be prevented and treated. An adequate intake of folic acid, iodine, vaccination, and adequate antenatal care are key.

8. India included in the list of countries account for the two-thirds of the world's preterm births.

\section{Materials and Methods}

This study was carried out in the Department of Obstetrics and Gynaecology, C.U. Shah medical college and hospital, Surendranagar over a period of two year. All antenatal women who had ultrasound sonography revealing congenital anomalies were included in the study.

Neonatal characteristics such as gestational age and type of congenital anomaly were included. Statistical analysis was done using SPSS software and reported as percentages wise deemed appropriate for variables.

\section{Results}

\section{Maternal characteristics}

\begin{tabular}{|l|c|c|}
\hline & Numbers & Percentage (\%) \\
\hline Age & & \\
\hline$<20$ years & 7 & 14 \\
\hline 20-30years & 29 & 58 \\
\hline$>$ 30years & 14 & 28 \\
\hline
\end{tabular}

\begin{tabular}{|l|c|c|}
\hline Parity & & \\
\hline Primigravidae & 20 & 40 \\
\hline Multigravida & 30 & 60 \\
\hline Gestational age & & \\
\hline $12-15$ weeks & 13 & 26 \\
\hline $16-20$ weeks & 37 & 74 \\
\hline
\end{tabular}

2. 2. Distribution of congenital anomalies

\begin{tabular}{|l|c|c|}
\hline \multicolumn{1}{|c|}{ Anomalies } & Number & $\begin{array}{c}\text { Percentage } \\
(\mathbf{\%})\end{array}$ \\
\hline Craniospinal & & 26 \\
\hline Anencephaly & 13 & 12 \\
\hline Hydrocephalus & 6 & 20 \\
\hline Spina bifida & 10 & 8 \\
\hline $\begin{array}{l}\text { Arnold chiari } \\
\text { malformation }\end{array}$ & 4 & 8 \\
\hline $\begin{array}{l}\text { Sacrococcygeal } \\
\text { teratoma }\end{array}$ & 4 & 10 \\
\hline Holoprosencephaly & 5 & 10 \\
\hline Musculoskletal system & & 5 \\
\hline Club foot & & 6 \\
\hline $\begin{array}{l}\text { Anterior abdominal } \\
\text { wall defect }\end{array}$ & 3 & \\
\hline Gastrochisis &
\end{tabular}

\section{Fetal outcome}

\begin{tabular}{|l|c|c|}
\hline Abortion & 49 & 98 \\
\hline Hysterotomy & 1 & 2 \\
\hline
\end{tabular}

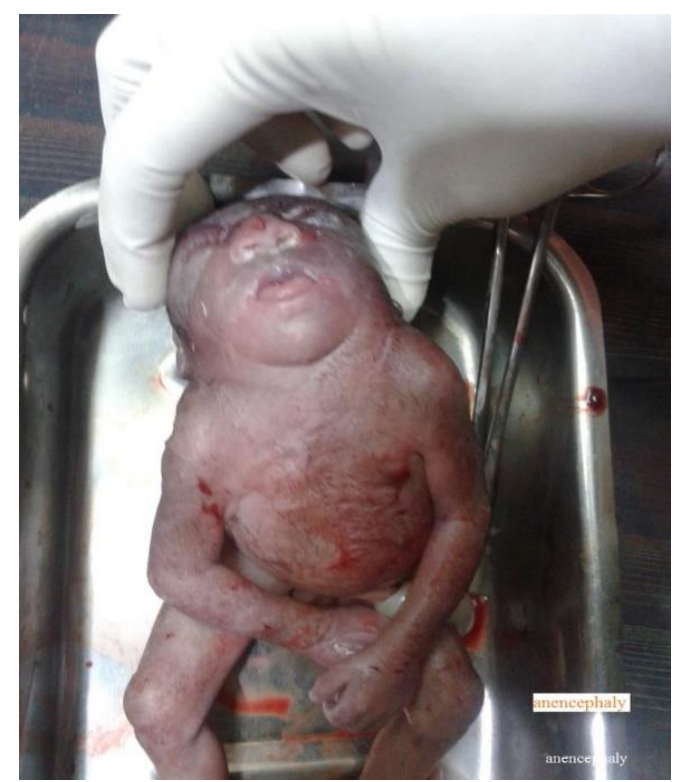

Fig. 1: Anencephaly 


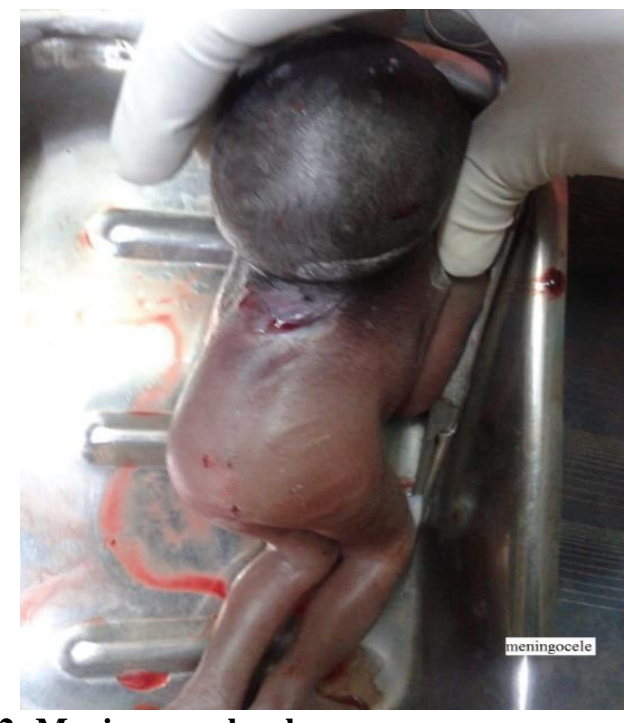

Fig. 2: Meningomyelocele

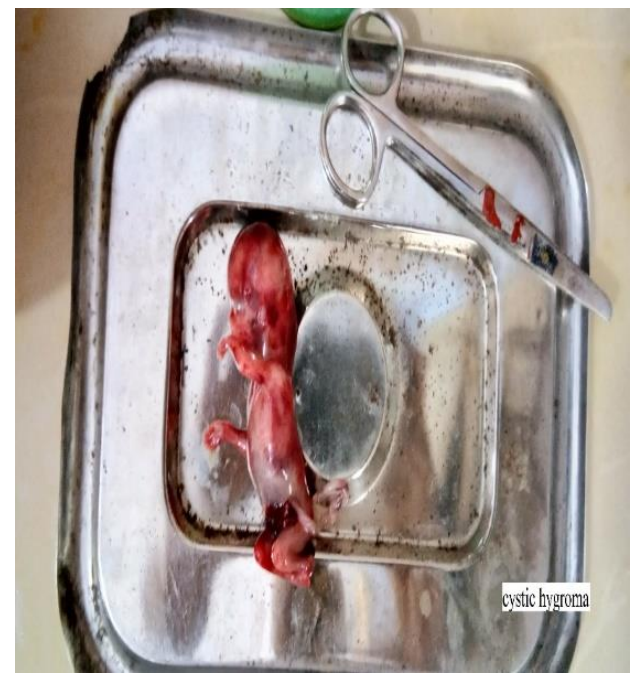

Fig. 3: Cystic hygroma

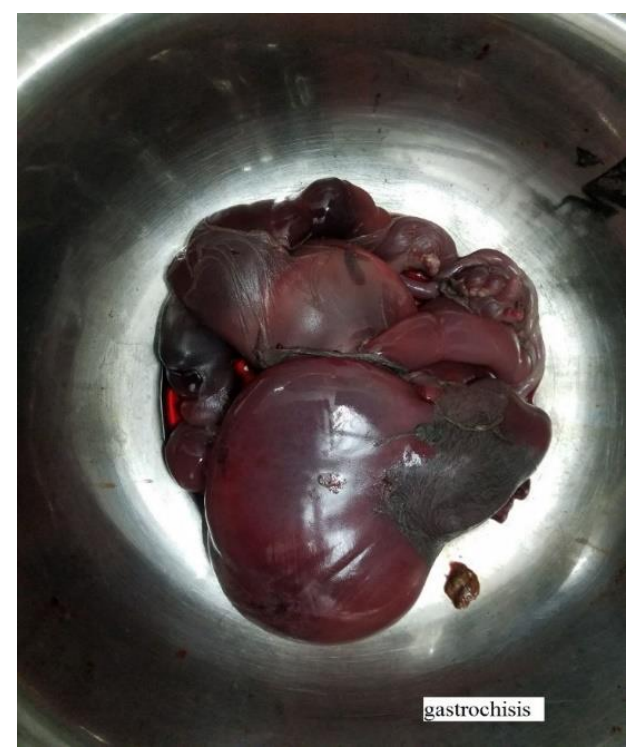

Fig. 4: Gastroschisis

\section{Discussion}

This study was done to determine the incidence of congenital anomalies in C.U. Shah medical college and hospital, Surendranagar. Birth defects have become important causes of perinatal mortality in developed countries as well controlled infectious and nutritional causes, and will soon become an important determinant of perinatal mortality in developing countries. There are no reliable estimates that how many number of children who were born with a serious congenital disorder were either due to genetic or environmental. In this study, the incidence of congenital anomalies was 2.48. These findings are comparable to similar studies from India, which reported an incidence of $2.73 \%$ and $1.8 \% .^{23,24}$

Our hospital being a tertiary care centre, which is strictly referral, usually gets complicated cases and hence the prevalence in the hospital cannot be projected in to total population.

Out of total deliveries in two years, 150 fetuses were born with congenital anomalies. Incidence being in\%, the commonest congenital anomalies involving CNS anomaly (84\%), most common anomaly in CNS is Anencephaly. Second most common is musculoskeletal system.

In terms of mode of delivery, most of the anomalous fetus $(98 \%)$ aborted through vaginal route and only one cases aborted with hysterotomy (2\%).

Despite of good antenatal care and various projects on obstetrical care, rate of congenital anomaly is very high. Women in reproductive age group should be counseled about the benefits of folic acid supplementation especially preconceptional in the high risk group. Rubella vaccination should be recommended for adolescent girls and in the early postpartum period.

\section{Conclusion}

Congenital anomalies in Indian population is very high. Anomalous child has negative impact on mental status of not only mother, father but whole family. Mother is much more attached to upcoming child, being anomalous cause much more depression. This study indicates the high rate of congenital abnormalities in our society and points toward the need to maintain a congenital malformation registry. As the prevalence in the hospital [being a tertiary care centre], cannot be projected in to total population, community base studies are needed to determine the exact prevalence of congenital anomalies.

\section{References}

1. Birth Defects Registry of India - A 'Saving Babies' Project. Available at:

http://www.medindia.net/news/health watch/BirthDefects-Registry-of-IndiaA-Saving-Babies-Project783891.

2. World health organization. Management of birth defects and haemoglobin disorders: Report of a Joint WHOMarch of Dimes meeting. Geneva, Switzerland, Geneva: WHO;2006. 
3. Victor B. Penchaszadeh. Preventing Congenital Anomalies in Developing Countries. Community Genet. 2002;5:61-69.

4. Christianson AL, Howson CP, Modell B. White Plains. New York, USA: March of Dimes Birth Defects Foundation; 2006. [Last accessed on 2012 Feb 24]. March of dimes global report on birth defects: The hidden toll of dying and disabled children. Available from: http://www.marchofdimes.com

5. World health organization. Management of birth defects and haemoglobin disorders: Report of a Joint WHOMarch of Dimes meeting. Geneva, Switzerland, Geneva: WHO; 2006.

6. Diav-Citrin O, Koren G. Nausea and Vomiting of Pregnancy: State of the Art 2000. Toronto, Ontario, Canada: The Motherisk Program, the Hospital for Sick Children; 2000. Human teratogen: A critical evaluation.

7. Ordóñez MP, Nazer J, Aguila A, Cifuentes, et al. Congenital malformations and chronic diseases of the mother. Latin American Collaborative Study of Congenital Malformations (ECLAMC) 1971-1999. L Rev Med Chil. 2003;131:404-11.

8. Fetal care research foundation. Available at: http://www.fcrf.org.in/fcrf_svcs.asp

9. Media centre. Congenital anomalies, Fact sheet $\mathrm{N}^{\circ} 370$ October 2012 Available at: http://www.who.int/mediacentre/facts heets/fs370/en/index.html

10. International Institute for Population Sciences (IIPS); Macro International National Family Health Survey (NFHS-3), 2005-06. Vol. 1. India, Mumbai: IIPS; 2007.

11. Government of India. Sample registration system of India. Office of Registrar General of India. Ministry of Home Affairs. GOI. 2007 Oct;42:1-6.

12. Ghosh S. Down syndrome in India. $\mathrm{Br}$ Med J. 1967;3(29):309-1.

13. World Health Organization. Country profile on reproductive health in Bangladesh. Geneva: WHO;2003.

14. Al-Riyami IM, Al-Busaidy IQ, Al-Zakwani IS. Medication use during pregnancy in Omani women. Int $J$ Clin Pharm. 2011;33:634-41.

15. Bittles AH. Global prevalence of consanguinity. 2009. [cited 2012 Feb 18]. Available from: http://www.consang.net/index.php/Global_prevalen ce.
16. Källén K. Multiple malformations and maternal smoking. Paediatr Perinat Epidemiol. 2000;14:227-33.

17. Sharma R, Kapoor B, Verma U. Drug utilization pattern during pregnancy in North India. Indian $\mathrm{J} \mathrm{Med}$ Sci. 2006;60:277-87.

18. Sharma R, Verma U, Sharma CL, Kapoor B. Selfmedication among the urban population of Jammu city. Indian J Pharmacol. 2005;37:37-45.

19. Preventing Birth Defects in India. Available at: www.epw.in/commentary/preventingbirth-defectsindia.html

20. Hannah Blencowe, Simon Cousens, Bernadette Modell, Joy Lawn. Folic acid to reduce neonatal mortality from neural tube disorders. Int J Epidemiol. 2010;39:1110-i121.

21. Nancy S. Green. Folic Acid Supplementation and Prevention of Birth Defects. J. Nutr. 2002;8:2356S2360S.

22. Controlling Birth defects: Reducing the Hidden Toll of dying and disabled Children in low-Income countries, Disease Control Priorities Project. Available at: www.dcp2.org/file/230/dcpptwpcongenitaldefects_web.p df

23. Chaturvedi P, Banerjee KS. Spectrum of congenital malformations in newborns from rural Maharashtra. Indian J Pediatr. 1989;56:501-7.

24. Taksande A, Vilhekar K, Chaturvedi P, Jain M. Congenital malformations at birth in Central India: A rural medical college hospital based data. Indian J Hum Genet. 2010;16(3):159-163.

How to cite this article: Sharma V.M, Airao B.B, Zala R. A, Pandya M.R. Pattern of various congenital anomalies: A hospital based study. Indian J Obstet Gynecol Res. 2018;5(4):549552. 